\title{
APPLYING SIMULATION TECHNIQUE TO MODEL DESIGN ITERATIONS
}

\author{
Wei-Chih Wang ${ }^{1}$, Tzong-Shiun Liau², and Jang-Jeng Liu² \\ ${ }^{1}$ Associate Professor, ${ }^{2}$ Graduate student, Department of Civil Engineering, \\ National Chiao Tung University, Hsin-Chu, Taiwan \\ Email: weichih@mail.nctu.edu.tw
}

\begin{abstract}
Improving the scheduling of the design project can greatly reduce the total duration of the project. However, appropriately representing the schedule of a design project is complicated chiefly because the design activities often have different degrees of information dependencies between each other. That is, design process involves a number of iterations across the design activities. This work develops a simulation-based model to incorporate the design iterations for generating the schedule of a design project. The proposed model is implemented using a simulation language and the benefits of the model are demonstrated by an example project.
\end{abstract}

Keywords: design iteration, simulation, design schedule, and design process.

\section{INTRODUCTION}

Many scheduling models have been developed to manage the duration of a construction project, but little effort has been made to control the schedule of the design project. However, slightly improving the control of the design schedule may greatly reduce the total duration of the project. Glavan and Tucker pointed out that about one third of public and private $\mathrm{A} / \mathrm{E}$ project missed cost and schedule target for some design-related problems [1]. A recent survey demonstrated that success of design process was the key to the success of project in the UK [2].

Current practice typically uses a bar chart method to represent the schedule of a design project. In the bar chart, each bar covers several months and represents a design activity. Some responsible project managers may further state points of expected percentage completions (such as, 25\%, 50\%, 75\% and $100 \%$ ) or control points (for example, drawing begun, drawings ready for engineering review, signing by project manager, incorporation of client's comments, and ready for bid/construction) as milestones in each design activity. Unfortunately, construction projects are frequently delayed because design deliverables (such as drawings, specifications, material take-off sheets and others) are delivered late.

Alternatively, a critical path method (CPM) network analysis may be used to schedule design activities. However, using CPM analysis for design projects is difficult mainly because design activities frequently have different degrees of information dependencies between each other. Namely, the design process involves a number of iterations. Thus, a large amount of design information passes among activities many times until owner's needs or regulatory requirements are met. Such iterative information dependency makes difficult to define the logical relationships between activities in the network as well as to evaluate the duration of each activity. Additionally, design resource utilization and productivity of designers are not easily incorporated into the schedule of a design project.

This work develops a simulation-based model to incorporate the design iterations for generating the schedule of a design project. The benefits of the model will be demonstrated by applying the model to a practical design project.

\section{PAST REARCH}

Considering design iterations and information dependency, Austin et al. [3-4] described a planning methodology (ADePT) to help plan the building design process. The core part of ADePT is a dependency structure matrix analysis that can help to order the design tasks into the optimum sequence to minimize the number of iterations within the multi-disciplinary design process. Furthermore, a computer tool, DePlan, has been developed by integrating the strategic nature of ADePT with the operational approach of Last Planner [5]. With a focus on viewing design as the flow of information, an Internet-based framework called the process-parameter-interface model was developed to address the design management issues associated with improving design process scheduling and increasing the efficiency of collaboration [6].

\section{DESIGN ITERATIONS}

Decisions made in the preceding activities may constrain the design search space in subsequent activities to such an extent that design may be 
sub-optimal or even infeasible. Accordingly, some design iteration loops may arise, possibly across a number of activities. Thus, iterations across activities should have a great impact on the ability to arrive at a precise duration estimate of a design project. Figure 1 displays the example of design iterations [7].

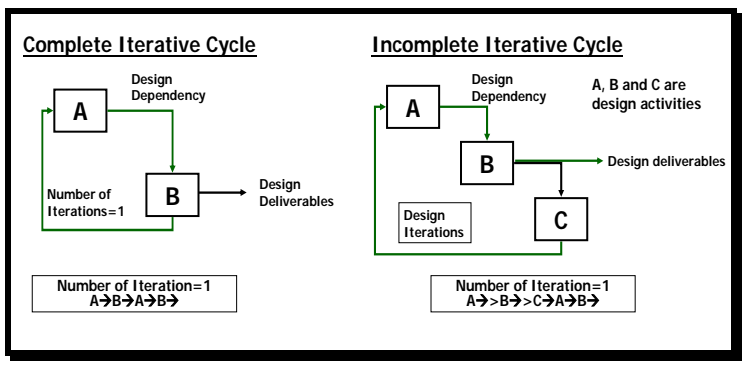

Figure 1. Example of design iterations

The occurrence of design iterations may be due to the following causes:

- Cyclic decision making process. - During designing, decisions often are made iteratively until the design deliverables meet the needs.

- Exchange of design information. - Design information often requires to be exchanged among intra-disciplines, inter-disciplines and multi-disciplines.

- Design review. - Design review always creates design iterations and certain activities may require to be revised to reflect the reviewing comments.

- Design rework. - Design rework produces design iterations because certain activities have to be performed again.

- Design change. - A design change may require extra design deliverables of an activity.

- Non-conformance of clients' requirements Nonconformance of design deliverables will also produce design iterations. This usually happen in schematic design phase that the project owner selects rejects the proposed alternative. An experienced designer will carefully produce the minimal design deliverables for ensuring that the proposed alternative meets the needs.

\section{PROPOSED MODEL}

The proposed simulation-based design schedule model consists of four modeling phases (See Figure 2), including representing design process (Phase I), developing simulation network (Phase II), identifying input parameters (Phase III), and selecting output variables and running simulation (Phase IV).

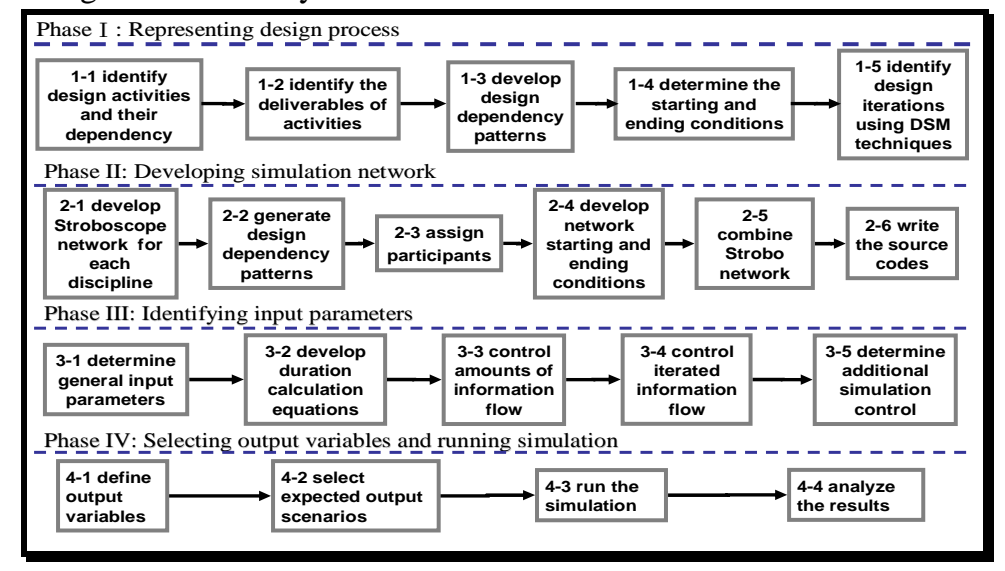

Figure 2. Modeling steps for developing design schedule

\subsection{Phase I: representing design process}

This phase is to systematically represent the design process of the design work by the following steps: (1) identify design activities and their dependencies, (2) define the deliverables of activities, (3) develop design dependency patterns, (4) determine the starting and ending conditions, and (5) identify design iterations by using dependency structure matrix (DSM) technique.

In this phase, several key points should be noted:

- The design activities discussed herein are end-item oriented or deliverable oriented. That is, the activities are the functional primitive tasks in the operational level. For example, the design activities are such as "preparing floor slab calculations" and "developing floor slab drawings". Conversely, those activities such as "prepare and develop design concept" and "coordinate design concept" are high-level design tasks that do not have definite outputs. And they are not considered in this study.

- Design dependency is the logical relationships between activities. A dependency indicates the information flow carrying with design deliverables.

- In this study, the design deliverables are classified according to the AIA (American Institute of Architects) standard practice and uniform drawing formats.

- Developing the patterns of design dependency 
is to facilitate establish a simulation-based network in a modular manner. The patterns can be "serial", "parallel” or "coupled".

- Determining the starting and ending conditions is to identify the major relationships among design disciplines. In a non-process facility building design, the architectural discipline usually leads the design project such that he delivers the plan to other disciplines and receives deliverables from them. Also, for example, $15 \%$ completion of floor plan may initiate the start of both ceiling design and finishes design activities; and 25\% initiates the start of structural design activity, and 35\% initiates the start of mechanical design activity [8]. In the proposed model, the percentage or amount of drawing completion can easily be accessed for initiating the starts of certain designated activities or disciplines.

- Design iterations can across the activities within a single discipline or multiple disciplines. DSM formulation is a matrix that can help represent activity iterations [9].

\subsection{Phase II: developing simulation network}

This phase is to establish a simulation-based network and write the source codes for the network. A simulation language, Stroboscope [10], is adopted to implement the simulation-relevant algorithms of design scheduling described in the proposed model. Stroboscope often is applied to dynamically access the state of the simulation and the properties of the resources involved in construction operations.

The modeling steps of this phase include: (1) develop Stroboscope network for each discipline, (2) generate design dependency patterns, (3) assign participants (e.g., such as architect, designers, or consultants), (4) develop network starting and ending conditions, (5) combine Stroboscope network of the individual networks, and (6) write the source codes.

Based on the cyclic nature of simulation, the iterative nature of design process can be easily captured. Also by incorporating the productivity rates of the design disciplines into a simulation-based model, expected outcomes of design duration can be calculated for measuring design performance.

In applying Stroboscope to this model, the COMBI nodes are used to represent design activities; QUEUE nodes store design resources (e.g., participants and drawings); and links carry the various types of design information. Other simulation control nodes can be found in Martinez [20].

\subsection{Phase III: identifying input parameters}

This phase is to identify the input parameters for running the Stroboscope model. Some of the parameters are Stroboscope's system maintained variables or control statements. The steps conducted in this phase include: (1) determine general input parameters, (2) develop duration calculation equations, (3) control amounts of information flow, (4) control iterated information flow, and (5) determine additional simulation control.

The major input parameters are such as the drawing amount, conversion factor, equivalent drawing quantity, unit rate, hour rate, participant breakdown ratio, and participant contribution ratio. Notably, the duration of a design activity includes the time to develop drawings and the time to synthesize the deliverables generated by other iterated activities. Steps (2) (4) are related to the programming of Stroboscope.

\subsection{Phase IV: selecting output variables and running simulation}

Before running the Stroboscope simulation model, this phase selects the output variables that are required by the model user. The steps include: (1) define output variables, (2) select expected output scenarios, (3) run the simulation, and (4) analyze the results.

\section{EXAMPLE DEMONSTRATION}

The example project is the design of auxiliary space for a factory building that is located in the Science-based Industrial Park, Hsin-Chu, Taiwan. The project involves architectural, structural, HVAC (mechanical) and electrical disciplines. Figure 3 displays the floor plan of the project. And Figure 4 shows the section of the mechanical room of the project.

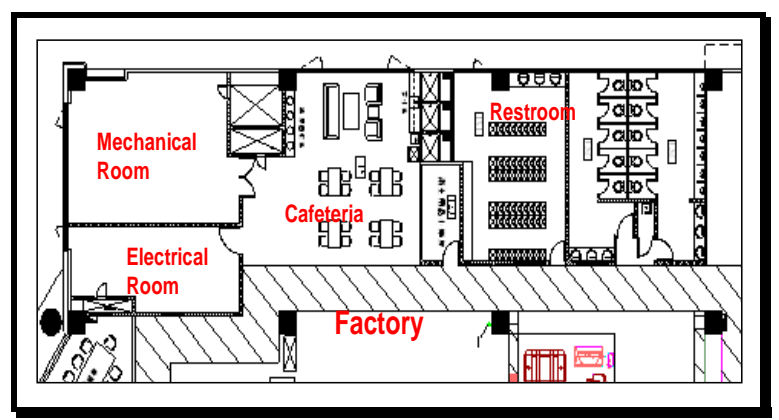

Figure 3. Floor plan of the example project

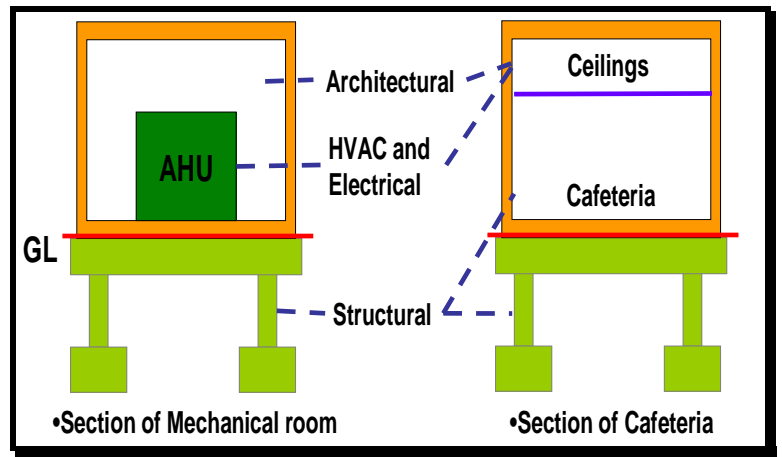

Figure 4. Section of mechanical room 


\subsection{Evaluations}

To evaluate the duration of this design project is based on the modeling steps summarized in Figure 2 and illustrated in Section 4. This section presents some of the major evaluations.

First, the left of Table 1 lists the identified design activities of each discipline for this design project. 31 activities involve in this project. The middle and right of Table 1 display the predecessors and iterated predecessors for each activity.

Then five iterations (iterations A, B, C, D, and E) can be found. Table 2 displays the description of each of the iterations. And Figure 5 presents the partitioned matrix for illustrating the iterations among design activities. Notably, the proposed model still works even without the use of DSM technique. Additionally, Figure 6 further uses a bar chart to represent these iterations.

Table 1. Predecessors and iterated predecessors of each design activity

\begin{tabular}{|l|l|l|c|}
\hline ID & \multicolumn{1}{|c|}{ Activity } & Predecessor & $\begin{array}{c}\text { Iterated } \\
\text { predecessor }\end{array}$ \\
\hline A1 & Architectural Design & & \\
\hline A2 & Floor plan design & & \\
\hline A3 & Exterior elevations design & A2 & A44 \\
\hline A4 & Wall sections design & A3 & \\
\hline A5 & Ceiling plan design & A3 & A30, A24 \\
\hline A6 & Restroom details design & A4 & \\
\hline A7 & Door and window details design & A6 & \\
\hline A8 & Cafeteria furniture design & A4 & \\
\hline A9 & Interior elevation design & A6, A5, A8 & \\
\hline A10 & Construction details design & A9 & \\
\hline A11 & Architectural design review & A10, A7 & \\
\hline A12 & Structural Design & & \\
\hline A13 & Structural calculations & A3 & A22 \\
\hline A14 & Foundation design & A13 & A19 \\
\hline A15 & Floor framing design & A14 & \\
\hline A16 & Beam details design & A15 & \\
\hline A17 & Column details design & A15 & \\
\hline A18 & Slab details design & A15 & \\
\hline A19 & Structural design review & A16, A17, A18 & \\
\hline A20 & HVAC Design & & \\
\hline A21 & HVAC calculations & A3 & \\
\hline A22 & AHU equipment design & A21 & \\
\hline A23 & Piping system design & A22 & \\
\hline A24 & Air duct plan design & A22 & \\
\hline A25 & AHU ductwork details design & A23, A24 & \\
\hline A26 & HVAC design review & A25 & \\
\hline A27 & Electrical Design & & \\
\hline A28 & Electrical switchgear calculations & A3 & \\
\hline A29 & Electrical switchgear design & A28 & \\
\hline A30 & Light fixture and wiring design & A29 & \\
\hline A31 & Emergency light design & A30 & \\
\hline A32 & Smoke detector design & A30 & \\
\hline A33 & Emergency exhaust duct design & A30 & \\
\hline A34 & Electrical design review & A31, A32, A33 & \\
\hline A35 & Design completed & \\
\hline
\end{tabular}

Table 2. Five identified iterations of the example project

\begin{tabular}{|c|c|}
\hline Iteration & Description of iteration \\
\hline $\mathrm{A}$ & $\begin{array}{l}\text { Intra-disciplinary design iteration: } \\
\text { Wall sections design (A4) will verify the } \\
\text { exterior openings size and height. That is, A4 } \\
\text { may produce design iterations for exterior } \\
\text { elevation design (A3). }\end{array}$ \\
\hline B & $\begin{array}{l}\text { Multi-disciplinary design iteration: } \\
\text { Air duct plan design (A24) and light fixture } \\
\text { design (A30) will produce the design }\end{array}$ \\
\hline
\end{tabular}

\begin{tabular}{|c|l|}
\hline & information for ceiling plan design (A5). \\
\hline C & $\begin{array}{l}\text { Interdisciplinary design iteration: } \\
\text { Assume that the AHU equipment design (A22) } \\
\text { produces design iteration for structura } \\
\text { calculations (A13) because the designated AHU } \\
\text { equipment loading exceeds the structural } \\
\text { loading capacity. }\end{array}$ \\
\hline D & $\begin{array}{l}\text { Intra-disciplinary design iteration: } \\
\text { Assume that the structural design review (A19) } \\
\text { produces re-design work to foundation design } \\
\text { (A14). }\end{array}$ \\
\hline E & $\begin{array}{l}\text { Intra-disciplinary design iteration: } \\
\text { Emergency light design (A31) and smoke } \\
\text { detector design (A32) will produce the } \\
\text { information for light fixture and wiring design } \\
\text { (A30). }\end{array}$ \\
\hline
\end{tabular}

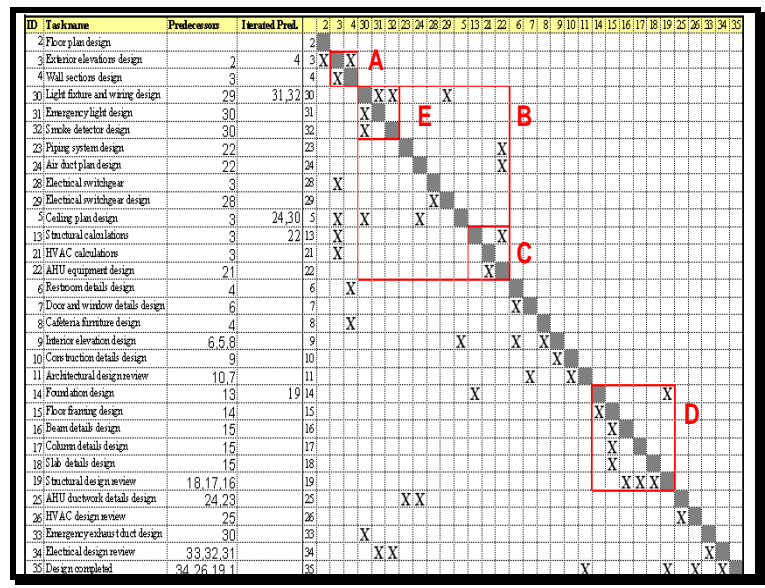

Figure 5. DSM after partitioning

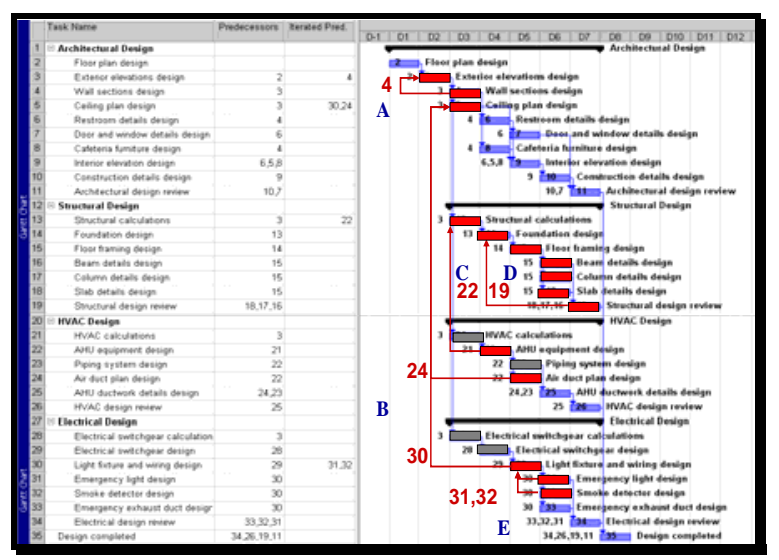

Figure 6. Representation of iterations using bar charts

Finally, a simulation-based network of this design project for this example project can be generated based on the aforementioned modeling phases (See Figure 7). In Figure 7, the integrated network includes all the design activities (represented by COMBI nodes), participants (including architect, designer, assistant designer, structural consultant, and many others), and other simulation control nodes for each discipline. Basically, the architectural discipline starts the work (i.e., activity A2 - floor plan design); and the design work is completed (i.e., activity A35) when all disciplines finish their activities. Notably, this network helps establish a series of programming codes. 


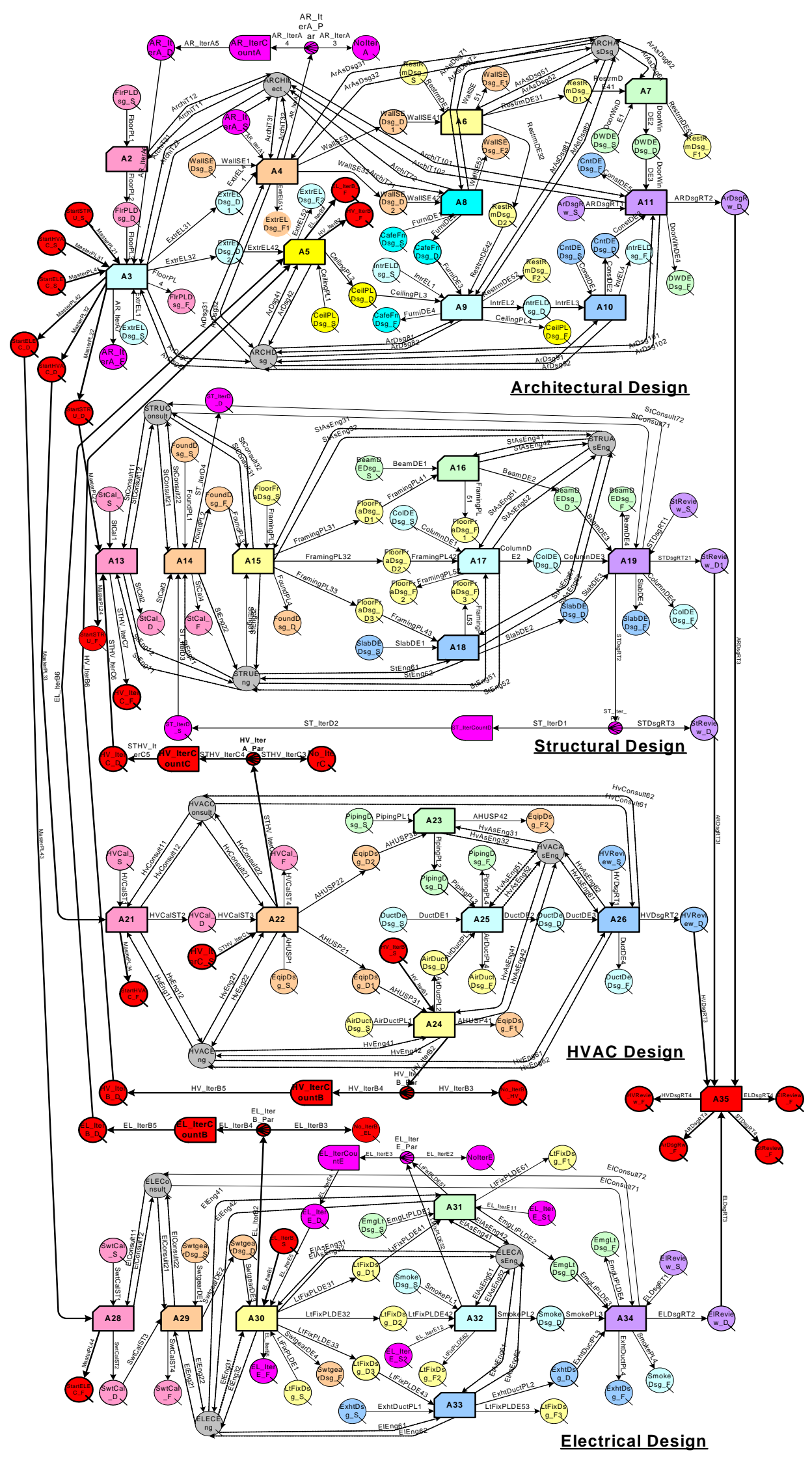

Figure 7. Simulation network of the example project

\subsection{Results}

After simulation, the total duration of this design project without considering the design iterations equals to 277.55 hours. And the critical path is the architectural and electrical disciplines. Figure 8 
presents a summary schedule for this run. When one time of design iteration is considered, the project duration increases to be 326.69 hours. A project design summary schedule is presented in Figure 9.

Another exercise is to find the suitable strategies of allocating the number of design participants by using sensitivity analysis (i.e., performing by different scenarios). For example, four scenarios ((1, $1,1),(2,2,2),(3,3,3)$ and $(4,4,4))$ of different numbers of the architectural participants (architect, designer, assistant designer) are evaluated under the one time of design iteration. The result (Figure 10) shows that the shortest project duration is 224.27 hours for scenarios $(3,3,3)$ and $(4,4,4)$. Apparently, scenario $(3,3,3)$ will be a better choice than scenario $(4,4,4)$ that requires higher costs.

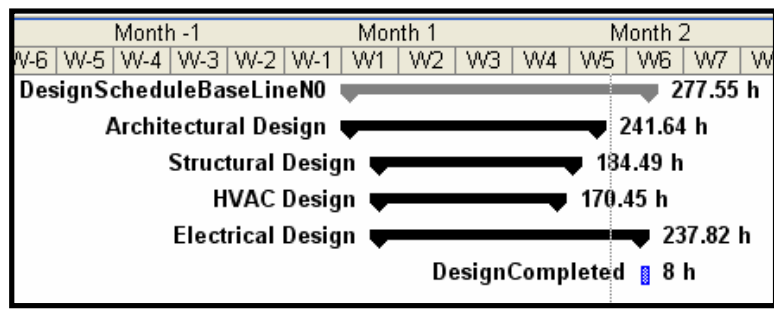

Figure 8. Project summary schedule (no iterations)

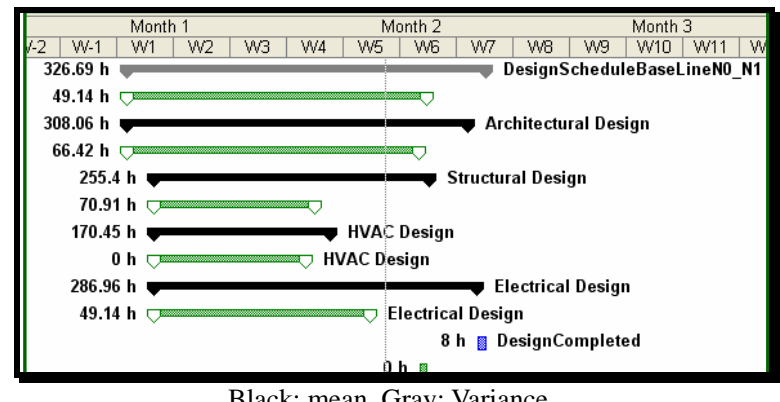

Figure 9. Project summary schedule (one iteration)

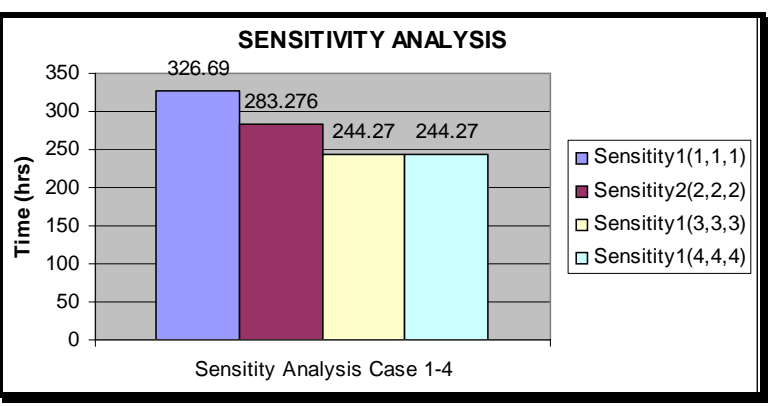

Figure 10. Project durations under different scenarios of architectural participants

\section{CONCLUSIONS}

While the bar chart and CPM are not suitable to model design schedule, this work innovatively applies the simulation technique to develop design schedule considering design iterations and design resources (such as participants and deliverables). Future research will further address the uncertainties in the model.

\section{REFERENCES}

[1] Glavan, J. R., and Tucker, R. L., "Forecasting Design-Related Problems - Case Study,” Journal of Construction Engineering and Management, ASCE, Vol. 117, No. 1, pp. 47-65, 1991.

[2] Nicholson, M. P. and Naamani, Z., "Managing Architectural Design - a Recent Survey," Construction Management and Economic, Vol. 10, pp. 479-487, 1992.

[3] Austin, S., Baldwin, A., Li, B., and Waskett, P., "Analytical Design Planning Technique: a Model of the Detailed Building Design Process,” Design Studies, Vol. 20, pp. 279-296, 1999.

[4] Austin, S., Baldwin, A., Li, B., and Waskett, P., “Analytical Design Planning Technique (ADePT): a Dependency Structure Matrix Tool to Schedule Building Design," Construction Management and Economics, Vol. 18, pp. 173-182, 2000.

[5] Chua, D.K.H., Tyagi, A., Ling, S., and Bok, S.H., "Process-parameter-interface Model for Design Management," Journal of Construction Engineering and Management, ASCE, Vol. 129(6), pp. 653-663. 2003.

[6] Choo, H. J., Hammond, J., Tommelein, I. D., Austin, S. A., and Ballard, G., "DePlan: a Tool for Integrated Design Management," Automation in Construction, Vol. 13, pp. 313-326, 2004.

[7] Eppinger, S., "Model-based Approach to Managing the Concurrent Engineering," Journal of Engineering Design, Vol. 2, No. 4, pp.283-290, 1991.

[8] Haviland, D., The Project - The Architect's Handbook of Professional Practice, AIA, Vol. 2, 1994.

[9] Smith, P. R., and Morrow, A. J., "Product Development Process Modeling,” Design Studies, Vol. 20, pp. 237-261, 1999.

[10] Martinez, J. C., STROBOSCOPE: State and Resource based Simulation of Construction Processes, $\mathrm{PhD}$ dissertation, University of Michigan, Ann Arbor, Mich., 1996. 